\title{
Intelligent System for Diagnosing and Fixing Automatic Washing Machine Malfunctions for Industrial Technical Education in Egypt
}

\author{
Mohamed. R. Alkotby \\ Department of Computer Teacher \\ Preparation \\ Faculty of Specific Education, \\ Damietta University, Egypt
}

\author{
Elsaeed. E. Mohamed Abd \\ Elrazek \\ Department of Computer Teacher \\ Preparation \\ Faculty of Specific Education, \\ Damietta University, Egypt
}

\author{
M.Z. Rashad \\ Department of CS \\ Faculty of Computer Science and \\ Information Technology \\ Mansoura University, Egypt
}

\author{
M.M.R. Elbasyouny \\ Department of Computer Teacher Preparation \\ Faculty of Specific Education, Damietta University, Egypt
}

\begin{abstract}
This paper aims to introduce a design of an intelligent system (IS) to help students of industrial technical education to diagnose and fix automatic washing machine malfunctions (AWMM), With the huge development in the manufacture of home appliances and their components, there has been a merger between several areas such as electronics specialist, refrigeration and air conditioning specialist. (They are the two specializations entrusted with repairing home appliances in the Egyptian labor market) Which has created a huge gap between the knowledge and skills of students of these two specialties in industrial technical education (ITE) schools and labor market requires. So it became necessary to employ the technology of artificial intelligence (AI) to help these students to keep abreast of the tremendous developments taking place in the field of manufacturing various home appliances, by designing the proposed intelligent system (IS) to save time and effort needed to process the various malfunctions of the automatic washing machine. We noticed that skills of students are improved in dealing with malfunctions.
\end{abstract}

\section{Keywords}

Intelligent systems (IS), Industrial Technical Education (ITE), Automatic Washing Machine Malfunctions (AWMM), Artificial Intelligence (AI).

\section{INTRODUCTION}

ITE is an important input for achieving economic development, as it aims to prepare trained human cadres capable of performing all work efficiently and with high capacity, through training and education at various levels of graded skill in a manner that meets the requirements of development plans and the labor market.

The experiences of different countries have proved that setting comprehensive development plans, facing challenges and solving problems cannot be achieved without the use of appropriate human resources, scientifically qualified, and technologically trained, to be able to keep pace with contemporary challenges [1]. As many problems arose with this type of education and its various specialties, because of the technological development that occurred in all fields, the most important of which is the high rate of unemployment of graduates of ITE to $81 \%$ [2].

This is due to the lack of compatibility between the knowledge and skills of the graduate and the requirements of the labor market and production. Which made this type of education a fertile environment for the spread of a number of serious social diseases, the most important of which is the high rate of some graduates of this type of education committing a number of different crimes $[3,4]$. Therefore the state has paid great attention in recent times to this type of education, and since the specialty of refrigeration and airconditioning and electronics was one of the specializations in the schools of ITE in Egypt, and with the tremendous development that occurred in the industry of automatic washing machines. Where all modern washing machines included a number of electronic circuits, which made the students of the refrigeration and air-conditioning specialization people incapable of diagnosing and fixing many of the faults of these washing machines. due to their lack of sufficient qualification to deal with the electronic circuits, and also the inability of the electronics specialization students to diagnose And fix these faults by themselves, due to their lack of awareness of the automatic washing machine components (Through the results of the survey study conducted by the researchers).

Whereas, the results of many previous studies have proven, including the study of each [5,9]. The effectiveness of using different computer systems in general and ISs in particular in fixing many problems in various fields, including raising the level of knowledge and skill for users of those systems in learning different skills, and dealing with malfunctions of different devices.

Accidents resulting from breakdowns of various exploding modern home appliances increase, which is due to the untrained and unqualified persons dealing with the faults and diagnosing them, Number of people were killed because of them. Many different newspaper sites published such Incidents $[10,12]$. 
That make researchers seek to think about designing an IS. That simulates the various methods, used by refrigeration and air-conditioning experts and electronics experts in diagnosing and fixing AWMM, and incorporating them within the proposed system, to help improve the knowledge and skills of students of specialization, which in turn contributes to narrowing the gap between the capabilities of ITE graduates and labor market requirements.

\section{AWARENESS OF PROBLEM}

The researchers noted the existence of many problems in accommodating students and training them in various specializations in ITE, especially the specialty of refrigeration and air conditioning. So it became clear that the capabilities and skills of its students are not compatible with the requirements and needs of the labor market, because of the tremendous development in the home appliances industry and the introduction of electronic circuits as an essential part of its parts. Which made students of this specialization unable to carry out the process of diagnosing and fixing the malfunctions of different devices. As a result to their lack of knowledge of electronics and how to deal with them and apply those in the actual reality and by reviewing the recommendations of many conferences, including the conference of "learn a Workmanship "organized by the Integrated Technology organization at Asyut University [13].

Which assured the need to pay attention to ITE to contribute to reduce unemployment rates for graduates of this type of education. Workshops were held during the conference to train in various fields, including refrigeration and air conditioning.

Study of Alkotby [9] confirmed the necessity of designing and using different systems in the educational process in ITE in particular because of the benefits they achieve and the necessity of employing them in various specializations.

The result of many related work such as [7, 8] Which emphasized the effectiveness of the use of ISs in the educational process, and the need to expand their design to serve and solve many problems related to different fields.

Study of Salem [14] confirmed that ITE institutions are unable to provide trained and qualified technician to comply with the needs of the labor market inside and outside. Because of the tremendous progress that occurred in all areas, and also assured the existence of a large gap between ITE programs and renewable requirements of the labor market, and recommended that Using modern software in the educational process to contribute to solving various problems.

Hence the necessity to think about finding suitable solutions to these problems in order to graduate students, who are qualified to deal with different devices and apply them in the field of some home appliances and help in the diagnosis and fixing of faults, and for this reason the researchers conducted a personal interviews. with the application of a survey application on (20) of ITE teachers, experts and specialists in the field of refrigeration and air-conditioning and electronics to determine the most important problems related to the diagnosis and fixing household appliances faults, and to identify the most vulnerable devices, as follows:

A) Personal interview with some teachers of ITE, specializing in electronics, and specializing in refrigeration and air conditioning with the aim of knowing the extent of the satisfaction of teachers of ITE about the level of students and their ability to diagnose malfunctions of the automatic washing machine, and then fixing them. The researchers confirmed through this interview that there are deficiencies in the practical exercises due to the following reasons:

- The tremendous development in the home appliance industry, and the including electronic circuits as an essential part of its parts, made students of both the refrigeration, air-conditioning and electronics specializations stand helpless in front of various malfunctions, unable to deal with them on their own, which doesn't deal with the requirements of the labor market .

- The electronics teachers themselves are not aware of the malfunctions of the air conditioning and refrigeration appliances, as well as the automatic washing machine and vice versa (electronic problems).

- The absence of a technical system that links the specialty of electronics with the specialty of refrigeration and air conditioning.

- Fear some refrigeration and air conditioning teachers of electronic circuits for the students safety and vice versa.

- Personal interview with some specialists and experts in the field of electronics, refrigeration and air conditioning, and the following is evident from them.

B) Personal interview with some specialists and experts in the field of electronics, refrigeration and air conditioning, and the following is the result:

- $95 \%$ of the specialists and experts in the field of electronics, refrigeration and air-conditioning are unable to diagnose and fix household appliances faults without completing each other.

- All the electronics and refrigeration and air conditioning specialists emphasized the high cost of replacing the electronic circuits for the automatic washing machine, which leads to the replacement of the entire washing machine.

- $\quad 90 \%$ of the owners of electronics, refrigeration and airconditioning maintenance workshops refuse to employ ITE graduates, because of the weakness of the skill of ITE graduates in diagnosing and fixing the faults of various household appliances, especially the automatic washing machine.

\section{RESEARCH PROBLEM:}

From all of the above it is clear that there is a severe deficiency in preparing ITE students specializing in refrigeration and air-conditioning and electronics. Which is the separation of the two specialties from each other, and the low level of knowledge and skills of their students in diagnosing and fixing faults of some common household appliances. The current research represents a serious scientific attempt to overcome this problem, by designing the proposed intelligent system to simulate the experts' thinking of diagnosing and fixing AWMM.

The study problem can represented in the following main question:

What are the stages of the proposed IS to help ITE students to diagnose and fix automatic washing machine faults? 
This main question divided into several sub-questions that researchers seek to answer, namely:

a) What are the common faults of home washing machines?

b) What skills should ITE students acquire to diagnose and fix automatic washing machine failures?

c) What is the proposed design of the IS for diagnosing and fixing automatic washing machine malfunctions?

d) What is the effect of applying the proposed IS on developing the knowledge and skills of ITE students to diagnose and fix common faults of automatic washing machines?

\section{RESEARCH HYPOTHESES:}

a) There is a statistically significant difference at the level (0.05) between the mean scores of students of the control group and the experimental group in the cognitive level in favor of the experimental group.

b) There is a statistically significant difference at the level (0. 05) between the mean scores of students of the control group and the experimental group in the skill performance and practical efficiency in favor of the experimental group.

c) There is an effect of using the proposed system at (0.05) level on the knowledge and skills of students of the experimental group.

\section{RELATED WORK}

Study of Alkotby [15] entitled "An Expert System for Assisting in Diagnosing and Fixing Common Cars Breakdowns

\section{(An Applied Case in Industrial Technical Education)".}

The study aimed to design an expert system to help automotive specialization students in ITE schools, to improve their skills in diagnosing and remedying automobile breakdowns, which in turn leads to narrowing the gap between the capabilities of students in that specialization and the requirements of the labor market.

The study found that there is a statistically significant difference at the level of significance (0.05), between the mean scores of the control group students (with a traditional teaching style) and the experimental group (with a teaching style using the proposed expert system) in skill performance and practical efficiency in favor of the experimental group.

Study of Bakeer [5] entitled "Photo Copier Maintenance Expert System V.01 Using SL5 Object Language".

The study aimed to design an expert system for the maintenance of photocopiers to save time, effort and cost needed to do so without need to an expert specialized in this field.

The study reached the effectiveness of the proposed system in maintenance of faults of cameras, and the agreement of the decisions that the system produces with the decisions approved by field experts towards these faults.

The current study agrees with this study in using the proposed IS to diagnose malfunctions, while it differs from it because it targets home appliances as well as its application in ITE, as it will differ from it in methods of representing knowledge.

Study of Albatish [16] entitled "ARDUINO Tutor an
Intelligent Tutoring System for Training on ARDUINO".

The study aimed to assist the trainees in overcoming the difficulties they face on dealing with the Arduino platform by describing the design of an intelligent educational system based on desktop applications and introducing the concept of the Arduino platform.

The study reached to design an intelligent learning system to help the trainees who want to learn skills in the field of Arduino and confirmed that the intelligent learning systems as a future teaching system that can replace the trainers, and saves material cost, time and effort, as it takes into account the individual differences between the trainees.

Study of Dardir [17] entitled "The external sufficiency of industrial secondary education in Egypt in the light of contemporary challenges".

The study aimed to monitor the contemporary challenges facing the labor market and its relationship to ITE, as well as to identify some international experiences in the field of developing secondary industrial education and benefit from it to develop it in Egypt.

The study revealed a weak correlation, between what the student studies in ITE and what he does in work after graduation. A lack of practical training in preparing the graduate to indulge in the labor market. In addition, study found a deep gap between this educational system and labor market requires. I assured that this type of education should not produce a technician concerned with the quality of production and aware of the foundations and principles of computer culture and modern technology.

Study of Al-Qenawy [18] entitled "Professional learning communities are an introduction to facing some of the problems of industrial secondary education schools in Egypt".

The study aimed to develop a suggested vision for how to face some of the problems of industrial secondary education schools in Egypt in the light of the entrance to professional learning societies.

The study found a weak professional integration among teachers of technical theoretical and practical subjects, as well as a weak level of practical training within the workshops and laboratories.

Study of El Shourbagy [19] entitled "Development of electronic computer technology courses for the Electronics and Computer department of industrial secondary schools in light of the requirements of the labor market and e learning".

The study aimed to develop the decisions of electronic computer technology for the department of Electronics and Computer in Industrial Secondary Schools. The study aimed to face requirements of the labor market and e-education. By identifying the technical skills necessary for the labor market and then determining the extent of their availability in the various courses. Moreover, preparing a proposed concept for two units of the proposed specialized study courses with elearning and e-learning strategies combined and then measure the effectiveness of these two units to provide students with aspects of cognitive learning at three levels: remembering, understanding and applying, and performing the included professional normative skills.

The study found that there is a statistically significant difference at the level of $(0.01)$ between the mean scores of the two experimental groups and the control group in the postapplication of achievement tests and performance positions in 
favor of the two experimental groups. In each of the two experimental units, which indicates the effectiveness of the proposed units and the need for decisions for development.

The current research agrees with previous studies to emphasize the importance of using ISs to facilitate the conduct of many works, while the current research employs them in diagnosing and fixing AWMM and applying its use in ITE.

\section{THE PROPOSED SYSTEM}

The stages of designing the proposed IS shown in figure (2):

\subsection{Stage1: Preparation and Data Collection}

At this stage, the researchers reviewed many previous studies and read many paper and electronic books to form a general perception of the proposed system. What it should be as the researchers conducted many personal interviews; that included the following categories. (experts and specialists in the field of electronics, experts and specialists in The field of refrigeration and air-conditioning, the owners of workshops for the maintenance and repair of electronic and home appliances, teachers of ITE specializing in electronics, refrigeration and air conditioning). In order to determine the most common and general AWMM on all brands. The researchers will have an initial conception of the proposed system and the logical sequence of the malfunction diagnosis process, and then extract expert knowledge and formulate it in the form of a set of rules, Rules for the various malfunctions of the automatic washing machines that were included in the proposed system.

\subsection{Stage 2: Design and Processing}

In it the researchers identified the languages, programs and tools used in designing the proposed IS, as well as identifying methods for representing knowledge within the proposed system, where the researchers used the merging between the forward and backward chaining sequence, and also formulated ways to deal with various faults in the form of a set of facts and rules. In order to create the knowledgebase, the researchers also designed the interface of the proposed system at this stage.

The researchers explains the languages, tools and programs used in designing the proposed system in the following:

\subsubsection{Programs used in designing the proposed system}

\section{A- Intellij idea}

\section{- Producing Company: Jet Brains}

- usage: It is used in writing the codes for the proposed system, as the program is distinguished by its ability to display system files while showing links between files and each other with its high ability to detect any errors in writing the code.

\section{B- Adobe Photoshop CS6}

- Producing Company: Adobe

- Usage: Used to adjust the images used in the proposed system, in order to get them out appropriately.

- Features: It helps in obtaining pictures with specifications and features according to the user's need.

\section{C-Adobe Dreamweaver}

- Producing Company: Adobe

- Usage: To design the proposed system screens and formats more professionally than before.

- Advantages: it is possible to achieve what the HTML; CSS codes do, but faster and more professional.

\section{D-Microsoft Visio program}

- Producing Company: Microsoft

- Usage: to draw the decision tree for the proposed system and other structures for the system.

- Features: You can use a very large set of different symbols for technical drawings or flowcharts, and allows the possibility to amend them in addition or delete at any time.

\subsubsection{Languages used in designing the proposed system:}

\section{A- JavaScript language:}

- It was used in many fields; In addition, it was used as an alternative to some languages of (AI) where it leads to the same result, but in an easier and simpler form. In addition, its products can run on any device and does not require special programs as it works on browsers, as well as the ability to be easily converted to applications that work on different devices such as (mobile, tablet).

\section{B- Html language:}

- It is an abbreviation for Hypertext Markup Language and was used in the design of the interfaces and the general look of the proposed system screens.

\section{C-CSS language:}

- It is an abbreviation of Cascading Style Sheets and was used to add effects and formats to the content of the proposed system screens.

\subsubsection{The tools used in designing the proposed system}

A-Angular Js: It serves as a framework for JavaScript to help use pre-programmed tools and libraries that serve as infrastructure for the proposed application or system.

\section{B-NODE JS:}

- It is a JavaScript runtime based on the JavaScript v8 engine that is an open source JavaScript environment.

\section{C-Firebase Real Time Database:}

- It is a database available from Google on the cloud, which allows the storage of data, so that the user can access it at any time and from anywhere via the Internet.

\section{D-Cordova:}

- To help in converting the proposed system files into mobile application

\section{E-Phone gap:}

- To help provide more than one version of the proposed system, whether to work on the desktop or iPhone devices. 


\subsection{Stage 3: System testing}

The researchers presented the proposed system to the experts and arbitrators, then they modified the proposed system according to their opinions and proposals, then he compared the results that the proposed IS produces with the results approved by experts and specialists in the fields of electronics, refrigeration and air conditioning. The researchers has confirmed the rules of work safely. The results of the system were in agreement with the results approved by experts and specialists in various fault cases.

\subsection{Stage 4: System usage}

In it, the researchers applied the proposed IS to the experimental group students that is shown in (7.2), Figure (1) shown the user interface of proposed IS.

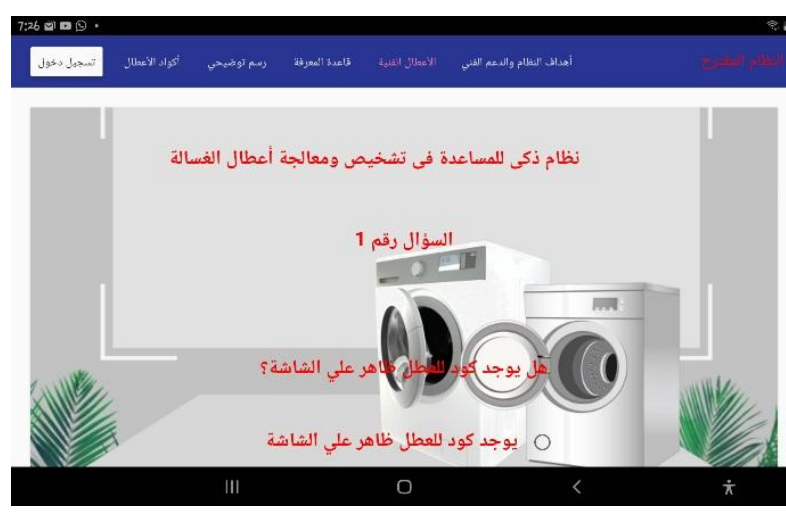

Fig (1) shows proposed IS user Interface

\subsection{Stage 5: System maintenance}

This stage includes the process of developing and updating the system. With malfunctions that occur on different automatic washing machines, during the design of the proposed system flexibility was considered, so that the system can be added or removed from it in a flexible manner that does not need large programming efforts. The researchers added a set of tools that enable the proposed system users to communicate with the system designer. As aids to provide technical support to users through several means of communication such as Facebook, WhatsApp, and others. 


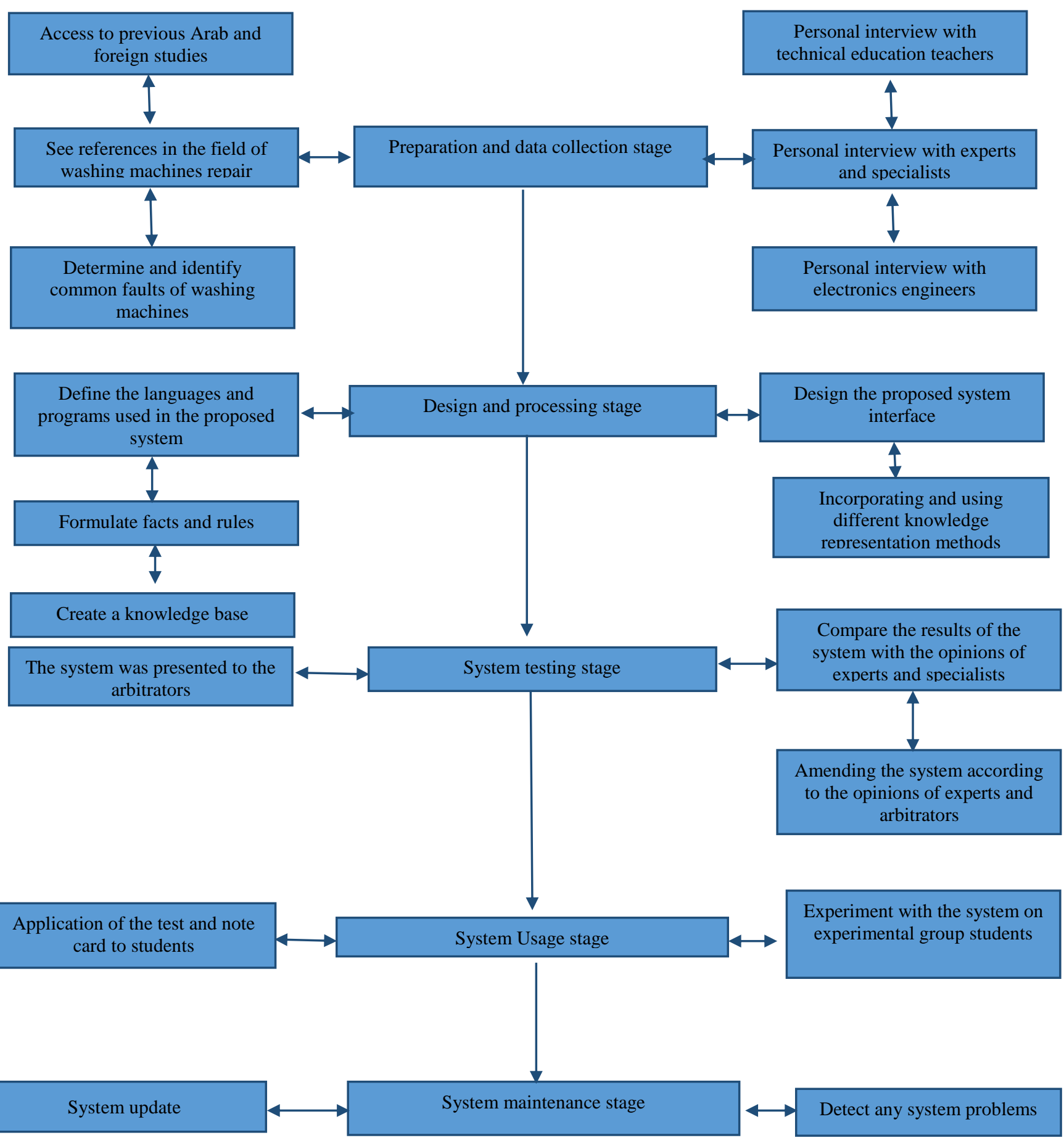

shows stages of proposed system 


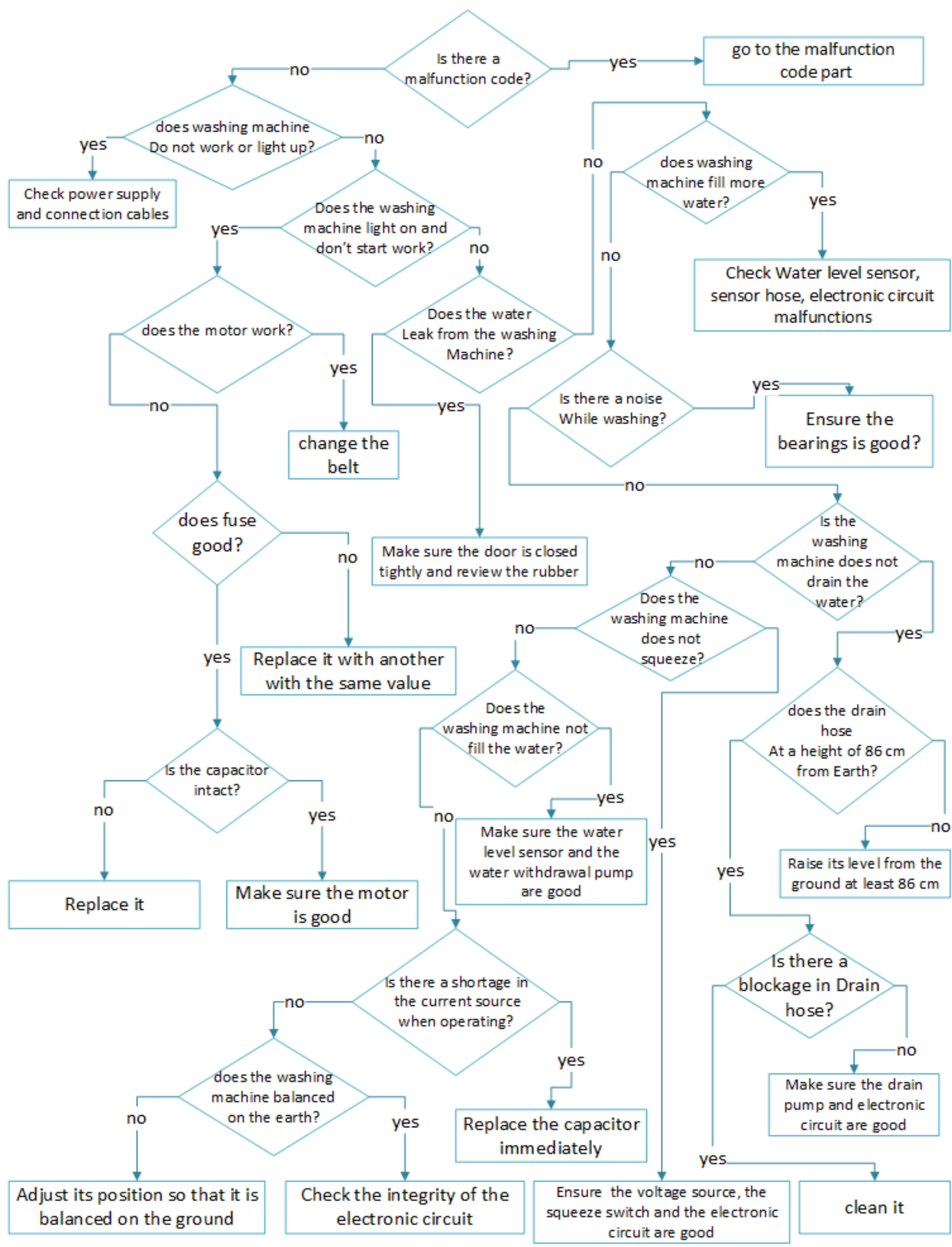

Fig (3) shows the failures of automatic washing machineFig (2) 


\subsubsection{The researchers has considered the following points in design the proposed system:}

- The simplicity of the graphical user interface in order not to confuse system users.

- Design the system in a flexible manner, so that it can be developed and updated at any time and from anywhere thanks to the presence of a knowledge base on cloud computing.

- Using the Arabic language in the proposed system to suit the needs of the current target group in the system (technical education students).

- Adding general instructions to help ensure the safety and security of system users.

- Providing the system with more than one version to suit different types of devices (computers, Android smart phones, iPhone devices).

\section{IMPLEMENTATION}

\subsection{The research sample:}

The sample of the research that was randomly chosen to measure the effect of applying the proposed IS to help ITE students specialize in electronics, refrigeration and air conditioning to improve their knowledge and raise their skills in diagnosing and fixing automatic washing machines faults in the following:

(16) Students from electronics specialization, (16) students from refrigeration and air conditioning students at Alexandria Advanced Technical School, were divided into two groups as follows:

a) Control group: (16) students, who did not use the proposed IS.

b) An experimental group: (16) students have used the proposed IS to diagnose and fix automatic washing machine malfunctions.

\subsection{Actual application of the experiment:}

\subsubsection{To answer the first question of the research questions:}

- What are the common faults of home washing machines?

Based on what was done in the personal interviews, the following common faults were identified that is shown in the research result.

\subsubsection{To answer the second and third questions of the research questions:}

- What skills should ITE students acquire to diagnose and fix automatic washing machine failures?

- What is the proposed design of the IS for diagnosing and fixing automatic washing machine malfunctions?

The researchers identified the Malfunctions and skills added in the proposed IS based on the results of interviews with the specialists and experts in the field of electronics, refrigeration and air conditioning, teachers of ITE. Researchers have followed the basic stages of designing the IS described previously.

\subsubsection{To answer the fourth question of the research questions:}

What is the effect of applying the proposed IS on developing the knowledge and skills of ITE students to diagnose and fix common faults of automatic washing machines?

The researchers applied the note card to the students of the control group. They applied the note card to the experimental group students, after using the proposed IS. Then collected the scores for the observation card for the control and experimental groups. They listed the students 'grades separately. They did a number of statistical processing using the spss program, in order to obtain the average scores for the students of the two groups and compare them with the aim of measuring the impact of using the proposed IS that is shown in table (1).

Table (1) shows the value of $t$ test and average scores of the students in the skills performance

\begin{tabular}{|c|c|c|c|c|c|}
\hline Groups & $\begin{array}{l}\text { Number } \\
\text { of } \\
\text { students }\end{array}$ & Average & $\begin{array}{l}\text { Standard } \\
\text { deviation }\end{array}$ & $\mathrm{T}$ & Sig \\
\hline control & 16 & 6.56 & 1.41 & \multirow{2}{*}{28.38} & \multirow{2}{*}{.000} \\
\hline Experimental & 16 & 16.87 & 0.341 & & \\
\hline
\end{tabular}

Table (1) shows the following:

The mean level of significance is less than (0.05). Which means rejecting the zero hypothesis and accepting the alternative hypothesis, meaning that there are statistically significant differences at $(0.05)$ between the control group and the experimental group in knowledge and skills for the experimental group. Since the average score is (16.87), which is greater than the average score of the control group (6.56), and the value of $\mathrm{T}(28.38)$ this confirms the validity of the research hypothesis.

This is due to the proposed IS which helps students to improve their knowledge and skills to deal with AWMM and fig 4 shows the difference between the degrees of both groups.

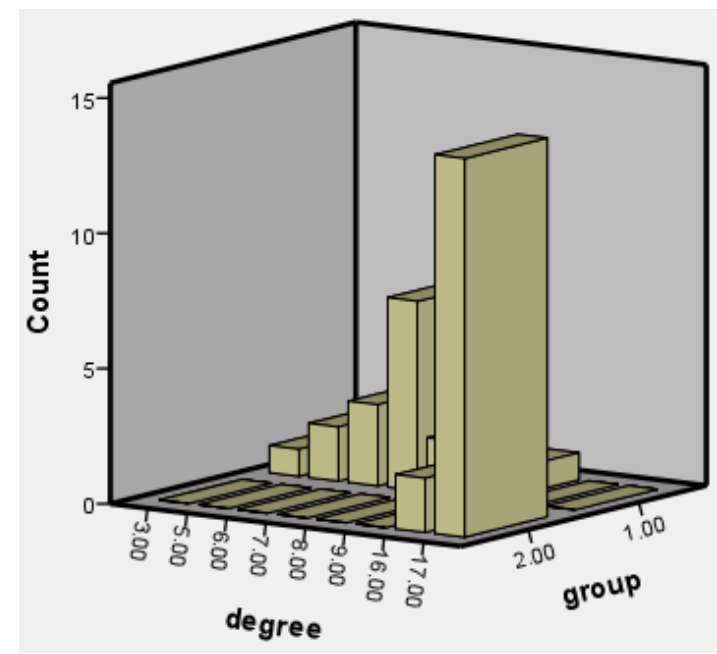

Fig (4) shows the degrees of control and expremental groups 


\section{RESEARCH RESULTS}

- Through the personal interviews that were conducted with the experts, the most common malfunctions of automatic washing machines and the skills required to deal with them were reached and included in the proposed system and were represented in the malfunctions of both (drainage pump, electronic circuit, imbalance, motor and belt of the washing machine, etc.that are shown in figure (3)).

- The proposed IS is designed to help diagnose and fix AWMM.

- It was clear that students 'knowledge and skills in dealing with ITEs have been improved after using the proposed system and thus contribute to reduce the gap between students' knowledge and skills and the requirements of the labor market.

- The research solved the problem of the separation of both the electronics and the refrigeration and air conditioning sectors.

\section{SEARCH RECOMMENDATIONS}

From all of the above, the research recommends the following points

a) The need to expand the use of ISs in the educational process in its various fields.

b) The necessity of changing the negative social perception of students and graduates of ITE.

c) Expanding the deployment of the proposed IS and trying to generalize its use in ITE schools, service centers, and repairing household appliances malfunctions.

d) Specialized companies adopt the proposed IS and try to integrate into fault diagnostic devices such as those used in diagnosing vehicle malfunctions.

e) Generalizing the use of the proposed IS in schools of ITE, which includes the specialty of electronics, refrigeration and air conditioning, in order to benefit from it.

\section{CONCLUSION AND FUTURE WORK}

The current research suggests the following studies

a) IS for diagnosing and repairing $\mathrm{CNC}$ machines for electrical specialization in ITE schools.

b) IS for diagnosing and repairing the malfunctions of the turning machines to specialize the turning in ITE schools.

c) IS for diagnosing and repairing accurate medical devices.

\section{ACKNOWLEDGMENTS}

The researchers extend their sincere thanks, appreciation to all people who helped them in the various stages of designing the proposed IS, and the most important of them are electronic engineers and specialists in repairing home appliances and everyone who contributed to the completion and output of this work.

\section{REFERENCES}

[1] Ahmed, A.M., A proposed vision of the role of technological incubators in developing industrial technical education in Egypt in light of the experiences of some countries. Educational sciences, 2015. 4(23): p. $1-61$.
[2] Rashid, K.E.S.A., The development of industrial technical education programs in the light of the renewed requirements to qualify for the labor market is a future vision, in Department of Foundations of Education. 2011, cairo university: Institute of Educational Studies.

[3] Amar, E., Seized a fake neuroscientist at Kafr Shaikh who holds an industry diploma, in Masrawi. 2015.

[4] Habib, A.S., Technical Education in Egypt: Problems and Solutions. Administration Egypt, 2014.

[5] Bakeer, H.M.S., Photo Copier Maintenance Expert System V.01 Using SL5 Object Language. International Journal of Engineering and Information Systems (IJEAIS), 2017. 1(4): p. 116-124.

[6] Hasanein, H.A.A., An Intelligent Tutoring System for Developing Education Case Study (Israa University), in Computing and Information Systems 2018, Al-Azhar University-Gaza Faculty of Engineering \& Information Technology

[7] Khella, R.A., An Intelligent Tutoring System for Teaching French. International Journal of Academic Multidisciplinary Research (IJAMR), 2018. 2(2): p. 9-13.

[8] Al-Bayed, M.H., Intelligent Multi-Language Plagiarism Detection System. International Journal of Academic Information Systems Research (IJAISR), 2018. 2(3): p. 19-34.

[9] Mohamed R Alkotby, E.E.M.A.E.a.M.Z.R., An Expert System to Diagnose and Fix Common Car Breakdowns for Industrial Technical Education in Egypt. International Journal of Computer Applications 2018. 182(7): p. 3037.

[10] Hosny, E., Samsung pulls 3 million explosive washing machines from the market, in Alyoum Alsabaa. 2016.

[11] Awda, A., Household appliances disasters, in vetogate. 2017.

[12] Mail, D. A broken refrigerator caused the London tower disaster. 2017 [cited 2020 16-03-2020]; Available from: https://arabic.rt.com/world/883877

[13] Mohammed, O. Learn the workmanship ".. Conference for the development of technical education at Assiut University". 2017 [cited 2018 23/3/2018]; Available from:

http://www.masrawy.com/News/News_Regions/details/2 017/2/23/1033320

[14] Salem, E.Z.A.R., Developing industrial technical education in light of the knowledge economy requirements, in Department of Foundations of Education. 2018, Ain shams university.

[15] Alkotby, M.R.A.E.A.E., An Expert System for Assisting in Diagnosing and Fixing Common Cars Breakdowns(An Applied Case in Industrial Technical Education), in Computer Teacher Prepration .2018 ,Damietta University: Faculty of Specific Education.

[16] Albatish, I., ARDUINO Tutor : An Intelligent Tutoring System for Training on ARDUINO. international Journal of Engineering and Information Systems (IJEAIS), 2018. 2(1): p. 236-245.

[17] Darder ,F.E.A.M., The external sufficiency of industrial secondary education in Egypt in the light of 
contemporary challenges, in Department of Foundations of Education. 2019, Ain Shams University.

[18] Al-Qenawy, M.A.N., Professional learning communities are an introduction to facing some of the problems of industrial secondary education schools in Egypt, in Department of Foundations of Education. 2018, Mansura University: Faculty of Education.
[19] Al-Shourbagy, S.I.J., Development of electronic computer technology courses for the Electronics and Computer Division of industrial secondary schools in light of the requirements of the labor market and elearning, in Department of Curricula and Teaching Methods. 2015, Ain Shams University: Faculty of Education. 